\title{
Nutrition, lifestyle and colorectal cancer incidence: a prospective investigation of 10998 vegetarians and non-vegetarians in the United Kingdom
}

\author{
MA Sanjoaquin*,', PN Appleby', M Thorogood ${ }^{2}, J^{\prime}$ Mann $^{3}$ and TJ Key' \\ 'Cancer Research UK, Epidemiology Unit, University of Oxford, Oxford OX2 6HE, UK; ${ }^{2}$ Warwick Medical School, University of Warwick, Coventry, \\ CV4 7AL, UK; ${ }^{3}$ Department of Human Nutrition, University of Otago, Dunedin, New Zealand
}

In a cohort of 10998 men and women, 95 incident cases of colorectal cancer were recorded after 17 years. Risk increased in association with smoking, alcohol, and white bread consumption, and decreased with frequent consumption of fruit. The relative risk in vegetarians compared with nonvegetarians was 0.85 (95\% Cl: 0.55- I.32).

British Journal of Cancer (2004) 90, II8-121. doi:I0.1038/sj.bjc.660144I www.bjcancer.com

(c) 2004 Cancer Research UK

Keywords: colorectal cancer; vegetarian; nutrition; incidence; smoking

In Europe and most of the industrialised world, colorectal cancer is the third most common cancer in men after lung and prostate cancer and the second most common in women after breast cancer (Parkin, 2001). A genetic component of risk is well established (Cannon-Albright et al, 1988), but diet is widely thought to be the most important determinant of risk. Two major reports reviewed the association between meat consumption and colorectal cancer risk and agreed that the findings were inconsistent, but suggestive of a positive association (World Cancer Research Fund, 1997; COMA, 1998). Evidence that risk is reduced by a relatively high intake of fruit and vegetables, and/or dietary fibre, is suggestive but not conclusive (Fuchs et al., 1999; Michels et al., 2000; Terry et al, 2001; Bingham et al, 2003).

We aimed to examine the relationship of lifestyle and dietary factors with the incidence of colorectal cancer in a cohort that included a large proportion of vegetarians. In particular, we sought to examine whether the risk for colorectal cancer is lower in vegetarians than in meat-eaters, and low in participants who reported consuming relatively large amounts of fruit or vegetables and other foods high in fibre.

\section{SUBJECTS AND METHODS}

The Oxford Vegetarian Study (Appleby et al, 1999) is a prospective investigation of 11140 vegetarians and nonvegetarians who were recruited in the United Kingdom between 1980 and 1984. Participants were contacted through the Vegetarian Society of the United Kingdom, publicity in the national and local media, and word of mouth via participants already recruited. Non-vegetarian participants were recruited by the vegetarian participants, who

*Correspondence: Dr MA Sanjoaquin;

E-mail: Miguel.Sanjoaquin@cancer.org.uk

Received 31 July 2003; revised 26 September 2003; accepted 29 September 2003
Table I Baseline characteristics of the participants by sex, given as number (percentage) of participants except where indicated

\begin{tabular}{|c|c|c|c|}
\hline Characteristic & $\begin{array}{c}\text { Men } \\
(n=4162)\end{array}$ & $\begin{array}{c}\text { Women } \\
(n=6836)\end{array}$ & $\begin{array}{c}\text { Total } \\
(n=10998)\end{array}$ \\
\hline Median age at entry (years) & 34 & 33 & 33 \\
\hline $\begin{array}{l}\text { Smoking } \\
\text { Never smoker } \\
\text { Former smoker } \\
\text { Current smoker }\end{array}$ & $\begin{array}{l}1816(43.6) \\
1317(31.7) \\
1029(24.7)\end{array}$ & $\begin{array}{l}4103(60.0) \\
1618(23.7) \\
1115(16.3)\end{array}$ & $\begin{array}{l}5919(53.8) \\
2935(26.7) \\
2144(19.5)\end{array}$ \\
\hline $\begin{array}{l}\text { Alcohol } \\
\qquad 1 \text { unit/week } \\
\text { I-7 units/week } \\
>7 \text { units/week }\end{array}$ & $\begin{array}{r}948(22.8) \\
1194(28.7) \\
2020(48.5)\end{array}$ & $\begin{array}{l}2223(32.5) \\
3101(45.4) \\
1512(22.1)\end{array}$ & $\begin{array}{l}3171(28.8) \\
4295(39.1) \\
3532(32.1)\end{array}$ \\
\hline $\begin{array}{l}\text { Body mass index }{ }^{a}\left(\mathrm{~kg} \mathrm{~m}^{-2}\right) \\
\quad<20 \\
20-<22.5 \\
22.5-<25 \\
25+ \\
\text { Median }\end{array}$ & $\begin{array}{l}594(\mid 4.4) \\
1567(38.1) \\
126 \mid(30.6) \\
693(16.8) \\
22.4\end{array}$ & $\begin{array}{l}1781(26.6) \\
2806(41.9) \\
1407(21.0) \\
706(10.5) \\
21.4\end{array}$ & $\begin{array}{l}2375(22.0) \\
4373(40.4) \\
2668(25.0) \\
1399(13.0) \\
21.7\end{array}$ \\
\hline $\begin{array}{l}\text { Diet group } \\
\text { Non-vegetarians } \\
\text { Vegetarians }\end{array}$ & $\begin{array}{l}2565(61.6) \\
1597(38.4)\end{array}$ & $\begin{array}{l}3780(55.3) \\
3056(44.7)\end{array}$ & $\begin{array}{l}6345(57.7) \\
4653(42.3)\end{array}$ \\
\hline $\begin{array}{l}\text { Median dietary fibre intake }\left(g_{\text {day }}{ }^{-1}\right) \\
\text { Bottom third } \\
\text { Middle third } \\
\text { Top third }\end{array}$ & $\begin{array}{l}17.9 \\
27.3 \\
39.6\end{array}$ & $\begin{array}{l}16.5 \\
24.7 \\
35.0\end{array}$ & $\begin{array}{l}17.0 \\
25.7 \\
36.7\end{array}$ \\
\hline $\begin{array}{l}\text { Median animal fat intake }{ }^{c}\left(\mathrm{~g} \mathrm{day}^{-}\right) \\
\text {Bottom third } \\
\text { Middle third } \\
\text { Top third }\end{array}$ & $\begin{array}{l}25.5 \\
52.4 \\
74.7\end{array}$ & $\begin{array}{l}23.6 \\
45.2 \\
67.0\end{array}$ & $\begin{array}{l}24.8 \\
47.2 \\
70.6\end{array}$ \\
\hline
\end{tabular}

Body mass index is unknown for 183 participants. ${ }^{\text {b Dietary fibre intake (Southgate }}$ fibre) is unknown for 3052 participants. 'Animal fat intake is unknown for 1470 participants. 
Table 2 Relative risks $(95 \% \mathrm{Cl})$ for colorectal cancer associated with selected dietary and lifestyle factors

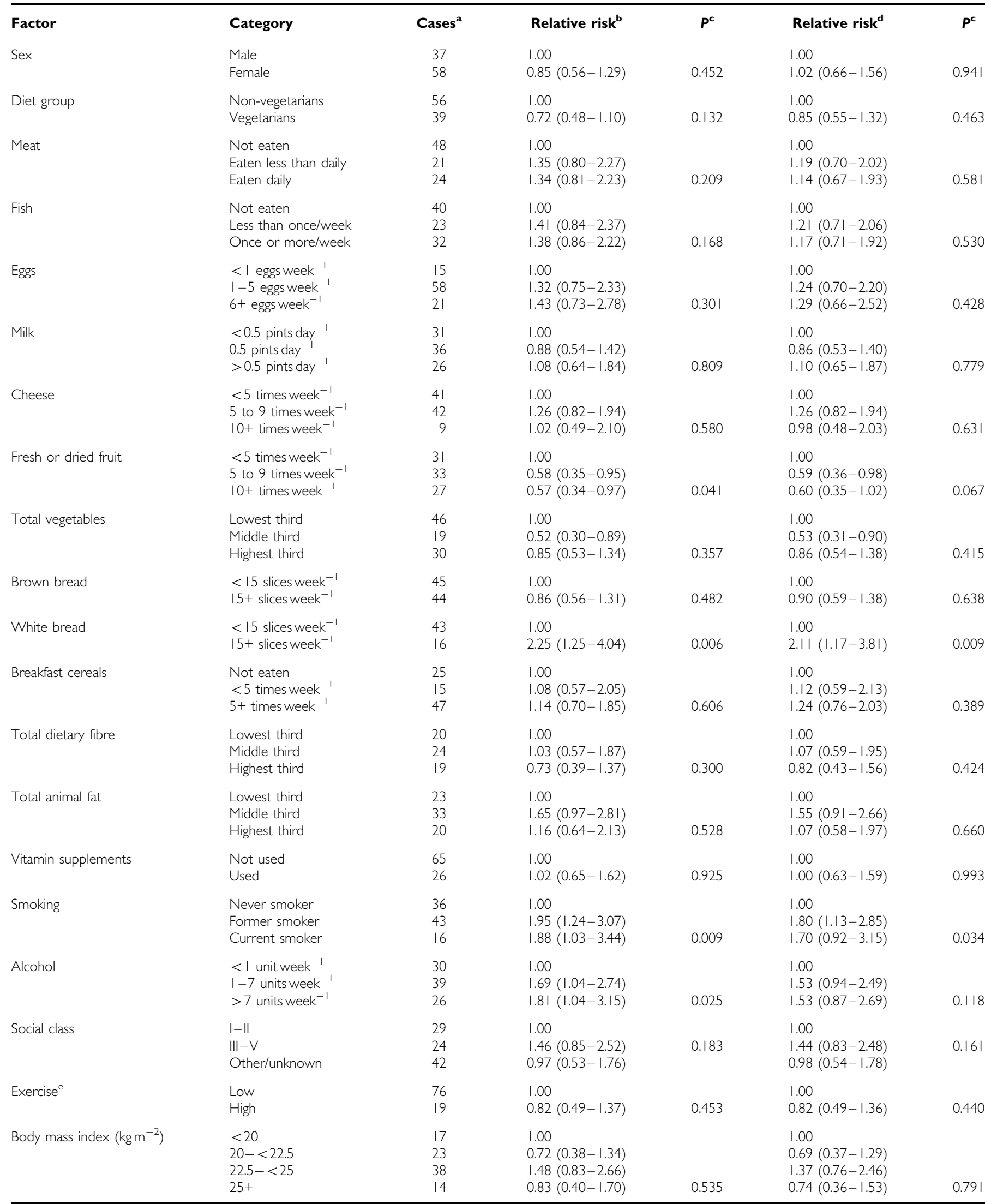

${ }^{a}$ The total number of cases does not always equal 95 because the level of the factor may be unknown for some cases. ${ }^{b}$ Adjusted for age and sex. ${ }^{c} P$ for trend (or heterogeneity between categories for sex and smoking). The test of linear trend simply ranks the categories I, 2, 3 etc. and excludes the other or unknown category for social class. ${ }^{d}$ Adjusted for age, sex, alcohol and smoking. ${ }^{e}$ High exercise is defined as sport, keep fit, running or cycling at least twice a week. 
were asked to nominate friends and relatives who ate meat, fish, or both.

Upon entry in to the study, participants completed a questionnaire including a simple food frequency questionnaire. Questions on other lifestyle factors related to health (smoking, alcohol consumption, and amount of exercise), date of birth, occupation, height and weight, and medical history (including illnesses related to the risk of cardiovascular disease and, for women, reproductive history) were also included. The validity of the questionnaire has been examined for estimating dietary fibre intake, but not for other nutrients (Gear et al, 1979). Participants were categorised into tertiles of the distribution of intake of total fat from animal foods (meat, eggs, milk, and cheese), as well as for dietary fibre derived from cereals, fruit, and vegetables. Participants were classified as vegetarians (including lacto-ovo-vegetarians and vegans) or nonvegetarians (meat eaters and people who ate fish but not meat), using their answers to questions on the consumption of meat, fish, dairy products, and eggs.

Each participant was flagged at the UK National Health Service central register and participants were followed for information on cancer registration and death. Participants were included in this analysis if they were aged 16-89 years at entry, had not been diagnosed with a malignant cancer before recruitment (except for nonmelanoma skin cancer, ICD9 code 173), and could be classified according to their smoking status and alcohol consumption. Participants were followed up to 31 December 1999, subject to censoring at age 90 .

Cox's proportional hazards model was used to estimate the association between selected nutritional and lifestyle factors and the risk of colorectal cancer. All incidence rate ratios were adjusted for age at recruitment (in 11 categories: $<40,40-44,85-89$ years) and sex. Further adjustments were made for smoking status (in three categories: never, former, and current smoker) and alcohol consumption (in three categories: non-/occasional drinker, $1-7 \mathrm{uweek}^{-1}$ and $>7 \mathrm{uweek}^{-1}$ ). The statistical analysis was performed using the STATA statistical package (StatCorp. 2001).

\section{RESULTS}

A total of 10998 participants were included in the analysis with an average follow-up of 17 years. There were 95 incident colorectal cancer cases, 39 in vegetarians and 56 in nonvegetarians. Table 1 shows the baseline characteristics of the participants. Median age at entry was 34 years for men and 33 for women. In all, $38 \%$ of men and $45 \%$ of women were vegetarians. The Standardized Incidence Ratio (SIR) for colorectal cancer compared to the general population of England and Wales was 0.91 (95\% CI: $0.74-1.12$ ). The SIRs for vegetarians and non-vegetarians were 0.81 (95\% CI: $0.58-1.11)$ and 1.00 (95\% CI: $0.76-1.30)$, respectively.

Table 2 shows relative risks (RRs) and confidence intervals, nutritional and lifestyle factors, and colorectal cancer risk, adjusted for age and sex alone and with further adjustment for smoking and alcohol. Vegetarians showed a moderately but nonsignificantly lower risk of colorectal cancer compared with the nonvegetarians ( $R R \quad 0.72,95 \%$ CI: $0.48-1.10$ ), but this association became weaker after adjusting for smoking and alcohol (RR 0.85, 95\% CI: 0.55-1.32). Among the nonvegetarians, there was no evidence of a positive association with the frequency of meat consumption. Among the other dietary factors, the only statistically significant associations with risk were for fruit and white bread consumption. Participants with the highest consumption of fresh or dried fruit experienced a reduction of colorectal cancer risk (RR 0.57, 95\% CI: $0.34-0.97, P$ for trend $=0.041$ ), although the association was no longer statistically significant after adjusting for smoking and alcohol. Participants eating
15 or more slices of white bread per week compared with those eating less than 15 had significantly higher risk $(\mathrm{RR}=2.25,95 \%$ CI: $1.25-4.04 ; P$ for difference between groups $=0.006$ ), which remained highly significant after adjusting for alcohol and smoking.

After adjusting for alcohol intake, both current and former smokers had an increased risk of colorectal cancer compared with the never smokers $(\mathrm{RR}=1.70,95 \% \mathrm{CI}$ : $0.92-3.15$ and $\mathrm{RR}=1.80,95 \%$ CI: $1.13-2.85$, respectively). Among the other lifestyle factors, social class, exercise, alcohol consumption, and body mass index were not significantly associated with the risk of colorectal cancer.

\section{DISCUSSION}

This prospective study had a wide variation in diet due to the inclusion of a large proportion of vegetarians. The main limitation is the relatively small number of colorectal cancer cases and the lack of sophistication of the food frequency questionnaire.

The present analysis did not find a significant difference in risk between nonvegetarians and vegetarians. Furthermore, no increase in risk of colorectal cancer was seen with higher meat consumption among nonvegetarians. Nevertheless, the lack of statistical association may reflect the relative small number of cases. A previous analysis of mortality in this cohort (Appleby et al, 2002) showed similar death rates for colorectal cancer in vegetarians and non-vegetarians based on 25 and 24 deaths from colorectal cancer, respectively. However, in a prospective investigation of Seventhday Adventists (Singh and Fraser, 1998), cancer of the colon was significantly more common in non-vegetarians than in vegetarians. It could be suggested that the nonvegetarians in our study represent a healthy group compared with the population at large, and that this might account for the lack of difference between the vegetarians and non-vegetarians; however, the SIR among nonvegetarians was exactly one.

Fresh or dried fruit consumption was found to be significantly associated with colorectal cancer risk, although this association became nonsignificant after adjusting for alcohol and smoking. An approximately $40 \%$ decrease in risk was seen in people eating fresh or dried fruit five or more times per week compared with persons eating less than this amount. We did not observe a significant association for brown bread and risk of colorectal cancer, but a two-fold increase in risk was detected in those consuming 15 or more slices of white bread per week. White bread consumption may be a marker of an unhealthy diet, although an adverse association of refined carbohydrates with risk has been noted before (Chatenoud et al, 1999). We did not observe a significant association between fibre and colorectal cancer risk; however, information needed to estimate dietary fibre intake was unavailable for 32 cases, and the results are compatible with a recent report of a reduction in risk with high fibre intake (Bingham et al, 2003).

Our study suggested that smoking was associated with an almost two-fold increase in risk of colorectal cancer, although this association was attenuated by adjusting for alcohol consumption. The apparent adverse effect of alcohol was also partially confounded by smoking. Both the WCRF report (World Cancer Research Fund, 1997) and a comprehensive review by Potter (1999) concluded that smoking and alcohol are probable risk factors for colorectal cancer.

\section{ACKNOWLEDGEMENTS}

We thank all the participants in the Oxford Vegetarian Study. This analysis was supported by Cancer Research UK. 


\section{REFERENCES}

Appleby PN, Key TJ, Thorogood M, Burr ML, Mann J (2002) Mortality in British vegetarians. Public Health Nutr 5: 29-36

Appleby PN, Thorogood M, Mann JI, Key TJ (1999) The Oxford Vegetarian Study: an overview. Am J Clin Nutr 70: 525S-531S

Bingham SA, Day NE, Luben R, Ferrari P, Slimani N, Norat T, ClavelChapelon F, Kesse E, Nieters A, Boeing H, Tjonneland A, Overvad K, Martinez C, Dorronsoro M, Gonzalez CA, Key TJ, Trichopoulou A, Naska A, Vineis P, Tumino R, Krogh V, Bueno-de-Mesquita HB, Peeters PH, Berglund G, Hallmans G, Lund E, Skeie G, Kaaks R, Riboli E (2003) Dietary fibre in food and protection against colorectal cancer in the European Prospective Investigation into Cancer and Nutrition (EPIC): an observational study. Lancet 361: 1496-1501

Cannon-Albright LA, Skolnick MH, Bishop DT, Lee RG, Burt RW (1988) Common inheritance of susceptibility to colonic adenomatous polyps and associated colorectal cancers. $N$ Engl J Med 319: $533-537$

Chatenoud L, La Vecchia C, Franceschi S, Tavani A, Jacobs DRJ, Parpinel MT, Soler M, Negri E (1999) Refined-cereal intake and risk of selected cancers in Italy. Am J Clin Nutr 70: $1107-1110$

COMA (1998) Nutritional aspects of the development of cancer. Report of the Working Group on Diet and Cancer of the Committee on Medical Aspects of Food and Nutrition Policy. London: The Stationery Office.
Fuchs CS, Giovannucci EL, Colditz GA, Hunter DJ, Stampfer MJ, Rosner B, Speizer FE, Willett WC (1999) Dietary fiber and the risk of colorectal cancer and adenoma in women. $N$ Engl J Med 340: $169-176$

Gear JS, Ware A, Fursdon P, Mann JI, Nolan DJ, Brodribb AJ, Vessey MP (1979) Symptomless diverticular disease and intake of dietary fibre. Lancet 1: $511-514$

Michels KB, Edward G, Joshipura KJ, Rosner BA, Stampfer MJ, Fuchs CS, Colditz GA, Speizer FE, Willett WC (2000) Prospective study of fruit and vegetable consumption and incidence of colon and rectal cancers. J Natl Cancer Inst 92: 1740 - 1752

Parkin DM (2001) Global cancer statistics in the year 2000. Lancet Oncol 2: $533-543$

Potter JD (1999) Colorectal cancer: molecules and populations. J Natl Cancer Inst 91: 916-932

Singh PN, Fraser GE (1998) Dietary risk factors for colon cancer in a lowrisk population. Am J Epidemiol 148: $761-774$

StatCorp (2001) Stata Statistical Software: Release 7.0.. College Station, TX: Stata Corporation.

World Cancer Research Fund (1997) Food, Nutrition and the Prevention of Cancer: a Global Perspective. Washington DC: Am Inst Cancer Res 